G. Wilmot, N. Bhimsan BSc, D.A. Rocke FRCP(Edin) FFA(SA), W.B. Murray MD(Stell) FFA(RCS)(Lon)

\title{
Intubating conditions and haemodynamic changes following thiopentone or propofol for early tracheal intubation
}

Intubating conditions and haemodynamic changes were studied $30 \mathrm{sec}$ after a fixed induction dose of thiopentone or propofol in patients scheduled for elective surgery. The hypnotic agent was preceded by the administration of papaveretum $10 \mathrm{mg}$ three minutes before induction and alcuronium $0.2 \mathrm{mg} \cdot \mathrm{kg}^{-1}$ at induction. Ease of intubation was graded and the study conducted in a randomised double-blind fashion. In the thiopentone group $(n=30)$ intubation was very easy in $73 \%$ compared with $79 \%$ in the propofol group $(n=29)$. In two patients in the propofol group the tracheas were moderately difficult to intubate but there were no failed intubations in either group. No patients recalled the intubation period on subsequent postoperative questioning. The immediate post-induction average systolic pressure in the thiopentone group decreased by $0.7 \%$ (range $15.9 \%$ increase to $25.3 \%$ decrease) whilst the postintubation systolic pressure increased by $6.3 \%$ (range - $31.5 \%$ increase to $24.2 \%$ decrease). In the propofol group there was a decrease in systolic pressure after induction (average $14.4 \%$; range $15.5 \%$ increase to $41.4 \%$ decrease, $P<0.05$ ) but the

\section{Key words}

ANAESTHETICS, INTRAVENOUS: thiopentone, propofol; INTUBATION, TRACHEAL: technique, cardiovascular responses.

From the Department of Anaesthetics, University of Natal, Congella, Durban, South Africa.

Address correspondence to: Professor D.A. Rocke, Department of Anaesthetics, University of Natal, P.O. Box 17039, Congella 4013, Durban, South Africa. Tel: (031) 2504328/9, Fax: (031) 251011.

Accepted for publication 9th November, 1992. subsequent pressor response to intubation was markedly attenuated compared with baseline (average systolic pressure decreased $15.5 \%$ (range $22.4 \%$ increase to $42.7 \%$ decrease)). Following intubation and maintenance, ventilation with nitrous oxide $70 \%$ and halothane $1 \%$ the systolic pressure decreased markedly in both groups with a greater reduction in the propofol group $(P<0.05)$. Compared with baseline there were increases $(P<0.0001)$ in heart rate in both groups from induction of anaesthesia to the end of study. The results show that early tracheal intubation can be undertaken following thiopentone and is accompanied by haemodynamic stability. Comparable intubating conditions are associated with propofol but the dose used resulted in a considerable decrease in systolic blood pressure afier induction.

Chez des patients programmés pour chirurgie non-urgente, les auteurs évaluent les conditions d'intubation et les changements hémodynamiques après linjection d'une dose d'induction fixe de thiopental ou de propofol. L'administration de l'hypnotique est précédée de papavérétum $10 \mathrm{mg}$, trois minutes avant linduction, et d'alcuronium $0,2 \mathrm{mg} \cdot \mathrm{kg}^{-1}$ lors de linduction. La facilité d'intubation est cotée et l'étude randomisée et à double insu. Dans le groupe thiopental $(n=30)$, lintubation est facile dans $73 \%$ des cas comparativement à $79 \%$ dans le groupe propofol $(n=29)$. Lintubation endotrachéale est de difficulté moyenne chez deux patients mais elle est toujours réussie dans les deux groupes. Aucun patient ne se souvient de l'intubation. En moyenne, la pression systolique immédiatement après linduction diminue dans le groupe thiopental de $0,7 \%$ (écart de $+15,9 \%$ à $-25,3 \%$ ) de 6,3\%. Dans le groupe propofol, on a noté une baisse de la pression systolique après lïnduction (moyenne 14,4\%; écart: de $+15,5 \%$ à-41,4\% $P<0,05$ ). Dans ce groupe, le réponse tensionnelle à lintubation est considérablement atténuée comparativement à la valeur initiale: la pression systolique en moyenne diminue de $15,5 \%$ (écart: de $+22,4 \%$ à $-42,7 \%$ ). Après l'intubation et pendant le maintien de l'anesthésie avec ventilation sous protoxyde d'azote $70 \%$ en halothane $1 \%$, la pression systolique a diminué considérable- 
ment dans les deux groupes avec une baisse plus importante dans le groupe propofol $(P<0,05)$. Si on réfêre aux valeurs initiales, on note des augmentations importantes $(P<0,0001)$ de la fréquence cardiaque dans les deux groupes du début de l'anesthésie à la fin de l'étude. Ces résultats montrent qu'une intubation précoce réalisée après thiopental s'accompagne d'une hémodynamique stable. Des condition dintubation comparables sont associées au propofol mais la dose utilisée ici provoque une diminution importante de la pression systolique après lïnduction.

In patients undergoing elective surgery for which tracheal intubation is required, non-depolarizing muscle relaxants are often preferred to depolarizing agents. The traditional method of using non-depolarizing relaxants is to ventilate the lungs manually for up to three minutes after their administration and before intubation. This delay allows time for the onset of action of the relaxant but may be associated with difficulty in maintaining the airway, gaseous distension of the stomach, unknown and variable tidal volumes and adverse effects of unwanted PEEP. Larger initial doses of non-depolarizing agents and priming have been used in order to facilitate earlier tracheal intubation but these methods have not been widely adopted. A technique which would facilitate early tracheal intubation without the need to use succinycholine with its many disadvantages would be of considerable benefit.

In a previous study we demonstrated that tracheal intubation could be undertaken without difficulty $30 \mathrm{sec}$ after the administration of thiopentone in a technique that required the co-administration of an opiate three minutes before induction and the addition of a nondepolarizing muscle relaxant with the hypnotic agent. ${ }^{1}$ Only one of the 25 patients in the study group proved to be moderately difficult to intubate. The dose of thiopentone used $\left(5 \mathrm{mg} \cdot \mathrm{kg}^{-1}\right)$ was $20 \%$ greater than the dose used routinely in our premedicated elective surgical patients. The technique was not associated with an increased incidence of recall or postoperative sore throat and an unexpected observation was the haemodynamic stability observed throughout the induction - early intubation sequence. The purpose of the present study was firstly to confirm the haemodynamic stability found in our previous study and, secondly, to determine whether the most recently introduced hypnotic agent, propofol, would provide the same conditions of ease of intubation and haemodynamic stability.

\section{Methods}

Following Institutional Ethics Committee approval, informed written consent was obtained from ASA I or II patients scheduled for elective surgery in whom tracheal intubation was to be undertaken. Oral lorazepam, 1-2 $\mathrm{mg}$, was given on the morning of the operation. After venous cannulation, the ECG and heart rate were monitored and systolic, mean and diastolic arterial pressures measured using a non-invasive blood pressure monitor (Critikon, Dinamap 1846 P). After baseline measurements patients received an intravenous injection of papaveretum $10 \mathrm{mg}$ and further haemodynamic measurements were made at one-minute intervals for three minutes during preoxygenation. Thereafter, alcuronium $0.2 \mathrm{mg} \cdot \mathrm{kg}^{-1}$ was administered followed immediately by either thiopentone $5 \mathrm{mg} \cdot \mathrm{kg}^{-1}$ or propofol $2.5 \mathrm{mg} \cdot \mathrm{kg}^{-1}$ given over ten seconds. Papaveretum, a mixture of purified opium alkaloids, and alcuronium, a curare alkaloid prepared from toxiferin with a duration of action of 15-20 $\mathrm{min}$, were studied because they are widely used in our institution.

Patients were randomized after baseline measurements to one of two groups to receive either thiopentone or propofol. Allocation was done by one of the investigators opening a presealed envelope which contained a number prepared from a list of random numbers. The study was conducted double-blind and the laryngoscopist (GW) was unaware of the induction agent used. In both groups, laryngoscopy commenced $30 \mathrm{sec}$ after completion of administration of the induction agent. Ease of intubation was noted on a five point scale $(1=$ very easy - intubation accomplished without any difficulty, an excellent view of the vocal cords and no additional measures such as external laryngeal pressure required; $2=$ not difficult - external laryngeal pressure required to facilitate intubation but the tracheal tube could be passed easily; 3 $=$ moderately difficult $-\mathbf{a}$ restricted view of the laryngeal inlet even with external laryngeal pressure and the tracheal tube passed with difficulty; $4=$ difficult - requiring a second attempt at laryngoscopy, a restricted view of the larynx even with external pressure and difficulty passing the tracheal tube; $5=$ failed) and the duration of intubation was timed from opening of the mouth to inflation of the cuff. A record was made if the patient coughed or bucked during intubation. All intubations were undertaken by the same person (GW) and the lungs were ventilated with halothane $1 \%$ and nitrous oxide $70 \%$ in oxygen for a further six minutes. Blood pressure and heart rate were recorded throughout this time at oneminute intervals.

On the day after the operation, patients were interviewed to determine the last recalled event before induction of anaesthesia and the first remembered postanaesthetic event. The incidence and severity of sore throat, nausea and vomiting were also noted. Data were analysed using repeated measures analysis of variance. To adjust for the initial differences (systolic, mean and 
diastolic blood pressures and heart rate) between the two groups the baseline values were used as covariates in the analysis and a value of $P<0.05$ was considered significant. Since significant group $X$ time interactions were apparent, the time effect was investigated within each group separately using repeated paired $t$ tests with Bonferroni adjustments $(P<0.005$ was considered significant for these interactions). The Chi-square test was used for categorical data and, where expected cell frequencies were less than 5, Fisher's Exact Test was used.

\section{Results}

Patients in the thiopentone group $(n=30)$ had a mean age of 39.8 (SD 14.1) yr, weight $63.6(8.6) \mathrm{kg}$ and male to female ratio of $17: 13$. The corresponding values for the propofol group $(n=29)$ were 43.1 (11.4) yr, 70.1 (13.4) $\mathrm{kg}$ and ratio 14:15. The average weights were different $(P<0.05)$.

There were no differences between the groups in the assessment of ease of intubation and no patient developed laryngospasm. In the thiopentone group intubation was classed as very easy in 22 patients (73.3\%) compared with 23 patients $(79 \%)$ in the propofol group. The remaining eight in the thiopentone group were classified as not difficult. Of the remaining six in the propofol group, four were classified as not difficult and two as moderately difficult. There were no failed intubations. Thirteen patients in the thiopentone group compared with 11 in the propofol group coughed during passage of the tracheal tube (NS) whilst no patients bucked during intubation. The mean (SD) duration of laryngoscopy and intubation in the thiopentone group was $10.0(8.5)$ sec compared with 9.5 (10.9) sec in the propofol group (NS). Six patients $(20 \%)$ in the thiopentone group complained of postoperative sore throat, compared with seven $(23 \%)$ in the propofol group (NS). No patient in either group recalled the period of intubation on subsequent questioning. Five patients experienced vomiting in the thiopentone group, compared with three in the propofol group (NS).

Systolic blood pressure changes as a percentage of baseline are depicted in Figure 1. There was a difference in the average baseline systolic blood pressures between the two groups (thiopentone - mean (SD) 137 (20.3) $\mathrm{mmHg}$; propofol $151(22.3) \mathrm{mmHg})(P<0.05)$. Adjusting for this initial systolic blood pressure difference by using the baseline pressures as covariates, there were group differences from four to $10 \mathrm{~min}(P<0.0004)$. In addition, group $\times$ time interaction was different $(P$ $<0.0002$ ) from four to ten minutes, with the propofol group having a greater decrease in blood pressure. In the thiopentone group there was no change in pressure between the control value and the post-induction and first post-intubation readings. Immediately after induction but

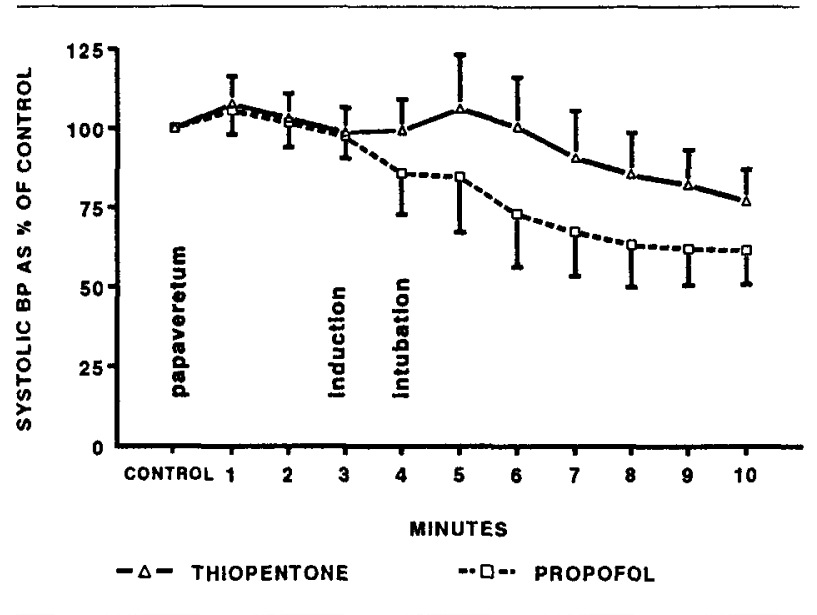

FIGURE 1 Systolic blood pressure as \% of control. Control is the average of three values taken before papaveretum - all other values are expressed as a percentage of the control, which is set as $100 \% .1,2,3=$ min after papaveretum; $4=$ one minute after alcuronium and induction agent; $5=$ one minute after tracheal intubation; $6-10=$ oneminute intervals.

before intubation the average decrease in systolic pressure was $1.3 \%$ (range: $12.9 \%$ increase; $13.4 \%$ decrease) compared with control values. Immediately after intubation the average systolic pressure increased $6.3 \%$ (range: $31.5 \%$ increase; $24.2 \%$ decrease). In the propofol group there was a decrease systolic pressure in the post-induction recording (average $14.4 \%$; range $15.5 \%$ increase to $41.4 \%$ decrease, $P<0.05$ ). Immediately following intubation there was little change in pressure. With the institution of maintenance anaesthesia blood pressure decreased in both groups. In the thiopentone group the average systolic pressure decreased $23 \%$ (range $0 \%$ to $40.5 \%$ decrease) whereas in the propofol group systolic pressure decreased $38.7 \%$ (range: $19.5 \%$ to $56.2 \%$ decrease). Following induction of anaesthesia there was a difference in systolic blood pressure values between the two groups at each observation time $(P<0.05)$. The changes in mean arterial and diastolic blood pressures paralleled the systolic changes.

As there was no difference in the baseline heart rates these are depicted as absolute values in Figure 2. The differences in heart rates between the groups were not significant at any stage. All observations from induction of anaesthesia until the end of the study showed increases in heart rate in both groups compared with control ( $P$ $<0.0001)$.

\section{Discussion}

The results of our study confirm both the ease of intubation and the haemodynamic stability associated with early tracheal intubation after induction of anaesthesia 


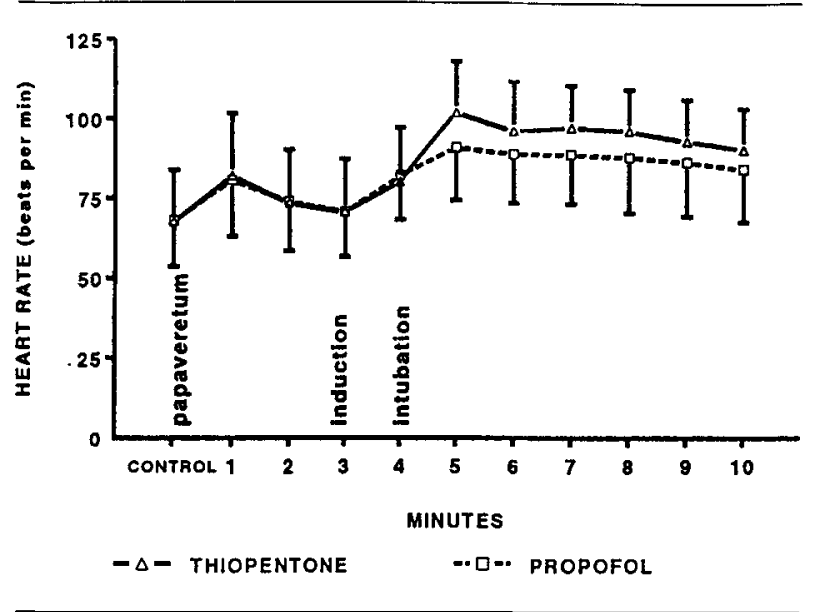

FIGURE 2 Changes in heart rate in beats per minute. Control is the average of three values taken before papaveretum - all other values are expressed as a percentage change of the control, which is set as $100 \%$. $1,2,3=$ minutes after papaveretum; $4=$ one minute after alcuronium and induction agent; $5=$ one minute after tracheal intubation; $6-10=$ one-minute intervals.

with thiopentone which was found in our previous report. ${ }^{1}$ This haemodynamic stability was obtained in spite of an increased dose of thiopentone given over only ten seconds. Whilst a similar ease of intubation was achieved with what was considered an equipotent bolus dose of propofol the associated haemodynamic changes were different both from the baseline propofol values and from the thiopentone group. In neither group was early intubation accompanied by an increased incidence of postoperative sore throat or recall although insufficient numbers of patients may have been studied to make a valid conclusion. $^{2}$

The most likely explanation for the haemodynamic stability with thiopentone is that the effects of endogenous catecholamines released by laryngoscopy and intubation counterbalanced the immediate decrease in blood pressure usually seen with thiopentone. The possibility of a synergistic interaction between the opiate and the barbiturate also exists. ${ }^{3}$ The technique outlined in this study also used drugs which are not available to all anaesthetists. We can only speculate that the use of a different opioid or muscle relaxant will not alter the findings. Further, the technique of administering the relaxant immediately before the induction agent may not be acceptable to some anaesthetists and the effects of differing combinations of drugs and their timing of administration will only be resolved in subsequent studies. In addition, although not studied and also given at varying time intervals before induction, the benzodiazepine premedication may have contributed to the pharmacological effects of the induction agents.
Although there have been no previous reports of early intubation after propofol induction in combination with opioids and non-depolarizing muscle relaxants other authors have attempted intubation after propofol alone. These studies were initiated by the observation that induction of anaesthesia with propofol with or without topical lidocaine was associated with a greater degree of relaxation of the vocal cords than after thiopentone. 4,5 Using propofol $2.5 \mathrm{mg} \cdot \mathrm{kg}^{-1}$ given over $20 \mathrm{sec}$ in a group of ASA I and II patients premedicated with diazepam and droperidol Keaveny and Knell found satisfactory intubation conditions in $60 \%$ of cases ${ }^{6}$ and in a further $35 \%$ patients mild coughing and/or bucking was noted. Unlike our study, where intubation commenced after 30 $\mathrm{sec}$, the induction to intubation time ranged from 25 to $170 \mathrm{sec}$ with a mean of $65 \mathrm{sec}$. Keaveny also commented upon the minimal decrease in mean arterial pressure two minutes after intubation. In a second study Hovorka and colleagues using propofol $2.5 \mathrm{mg} \cdot \mathrm{kg}^{-1}$ given over $30 \mathrm{sec}$ and supplemented by prior administration of lignocaine $1.5 \mathrm{mg} \cdot \mathrm{kg}^{-1}$ and alfentanil $30 \mu \mathrm{g} \cdot \mathrm{kg}^{-1}$ found intubation to be easy in only $22 \%$ patients. $^{7}$ In $10 \%$ intubation was difficult after propofol whilst in a control group who received thiopentone $5 \mathrm{mg} \cdot \mathrm{kg}^{-1}$ intubation was easy in $48 \%$. In this latter study intubation was carried out 45 sec after completion of the $30 \mathrm{sec}$ induction dose of propofol and it is possible that the shorter time of our induction resulted in higher peak brain levels which facilitated better intubating conditions. No detailed evaluation of the cardiovascular changes were documented. A final study of intubation after propofol without muscle relaxants was reported by Mulholland and Carlisle using propofol $2.5 \mathrm{mg} \cdot \mathrm{kg}^{-1}$ administered over $20 \mathrm{sec}{ }^{8}$ Intubation was undertaken $40 \mathrm{sec}$ after completion of the induction dose and conditions were unsatisfactory in $10 \%$. The authors were unable to intubate the tracheal in a further $31 \%$. The addition of lidocaine $1.5 \mathrm{mg} \cdot \mathrm{kg}^{-1}$ made no difference to the intubating conditions. Interestingly, the hypertensive response to laryngoscopy and intubation was not evident although only a single measure of mean arterial pressure taken one minute after intubation was reported. From the above studies it is apparent that satisfactory intubating conditions are not achieved when propofol is used alone.

In our previous study we chose a relatively high dose of thiopentone following clinical experience with the technique at lower doses. ${ }^{1}$ In the present study we compared thiopentone $5 \mathrm{mg} \cdot \mathrm{kg}^{-1}$ with propofol $2.5 \mathrm{mg} \cdot \mathrm{kg}^{-1}$. Fixed doses of thiopentone and propofol were chosen for purposes of the study and for comparison with our previous work. However, we have no reason to believe that a titrated dose would not result in similar findings. We chose a dose of propofol of $2.5 \mathrm{mg} \cdot \mathrm{kg}^{-1}$ because recent studies 
suggested a thiopentone:propofol potency ratio of $2: 1^{9}$ although others have found a potency ratio of 1.6 to $1 .{ }^{10}$ The dose of propofol used over a brief duration of time undoubtedly resulted in the marked decreases seen in systolic blood pressure. Hypotension following induction of anaesthesia with propofol has been well documented. ${ }^{11-13}$ Gold et al. reported a $14 \%$ decrease in systolic arterial pressure following propofol $2.5 \mathrm{mg} \cdot \mathrm{kg}^{-1}$ given over 20 sec. ${ }^{11}$ Coley et al. reported a decrease of $23 \%$ after 2.25 $\mathrm{mg} \cdot \mathrm{kg}^{-1}$ propofol given over 40-60 sec. ${ }^{12}$ Subsequent intubation in this latter study conducted two minutes after vecuronium was accompanied by a $28 \%$ increase in systolic arterial pressure and the authors concluded, despite no change in plasma noradrenaline concentrations, that the pressor response to tracheal intubation was not attenuated by propofol. ${ }^{12}$ In our study the absence of a pressor response to intubation was probably related to the dose and speed of propofol injection. The effect of reducing the speed of administration was examined by Peacock $e t$ al. who showed that whilst the duration of induction was longer, the total dose used and the decrease in arterial blood pressure were significantly reduced. ${ }^{13}$ Intubation was not undertaken in this study but plasma propofol concentrations were similar at loss of consciousness regardless of the speed of induction. It is possible that the same satisfactory intubating conditions could be achieved with a slower speed of induction and a lower dose of propofol whilst preventing the marked decrease in blood pressure following induction and at the same time obtunding the immediate post-intubation pressor response.

In conclusion we have confirmed both the satisfactory intubating conditions and the haemodynamic stability following early tracheal intubation after thiopentone. Whilst intubating conditions and prevention of the hypertensive response after an equipotent dose of propofol were equally satisfactory the increased dose over a short induction time coupled with the subsequent use of a volatile agent resulted in marked hypotension. The technique is not suitable for a rapid sequence induction in patients at risk of aspiration nor in the hypertensive patient without further study.

\section{Acknowledgements}

The authors wish to acknowledge the assistance of Ms Eleanor Gouws, Medical Research Council, Institute for Biostatistics, for the help with the statistical analyses and Mrs Camilla Singh for preparing the manuscript.

\section{References}

1 Marsh JE, Murray WB, Rocke DA. Early tracheal intubation with thiopentone in elective surgery. Br J Anaesth 1992; 68: 100-2.
2 Cormack RS. Awareness during endotracheal intubation (corresp). Br J Anaesth 1977; 49: 1175.

3 McKay $A C$. Synergism among I.V. anaethestics (Editorial). Br J Anaesth 1991; 67: 1-3.

4 McKeating K, Bali IM, Dundee JW. The effects of thiopentone and propofol on upper airway integrity. Anaesthesia 1988; 43: 638-40.

5 de Grood PMRM, Ruys AHC, van Egmond J, Booij $L H D J$, Crul JF. Propofol ('Diprivan') emulsion for total intravenous anaesthesia. Postgrad Med J 1985; 61 (Suppl 3): 65-9.

6 Keaveny $J P$, Knell PJ. Intubation under induction doses of propofol. Anaesthesia 1988; 43: Suppl. 80-1.

7 Hovorka J, Honkavaara P, Korttila K. Tracheal intubation after induction of anaesthesia with thiopentone or propofol without muscle relaxants. Acta Anaesthesiol Scand 1991; 35: 326-8.

8 Mulholland D, Carlisle RJT. Intubation with propofol augmented with intravenous lignocaine. Anaesthesia 1991; 46: 312-3.

9 Leslie $K$, Crankshaw DP. Potency of propofol for loss of consciousness after a single dose. Br J Anaesth 1990; 64: 734-6.

10 Grounds $R M$, Moore $M$, Morgan $M$. The relative potencies of thiopentone and propofol. Eur J Anaesthesiol 1986; 3: 11-7.

11 Gold MI, Abraham EC, Herrington C. A controlled investigation of propofol, thiopentone and methohexitone. Can J Anaesth 1987; 34: 478-83.

12 Coley $S$, Mobley KA, Bone ME, Fell $D$. Haemodynamic changes after induction of anaesthesia and tracheal intubation following propofol or thiopentone in patients of ASA Grade I and III. Br J Anaesth 1989; 63: 423-8.

13 Peacock JE, Lewis RP, Reilly CS, Nimmo WS. Effect of different rates of infusion of propofol for induction of anaesthesia in elderly patients. Br J Anaesth 1990; 65: 346-52. 